\title{
Clinical and USG Findings of Patients Presented with Breast Pain
}

\section{H. N. Ashikur Rahaman ${ }^{1 *}$, Shravana Kumar Chinnikatti²}

${ }^{1}$ Registrar, Dept. of Clinical Oncology, Enam Medical College \& Hospital, Savar, Dhaka, Bangladesh

${ }^{2}$ Senior Consultant, Dept. Of Clinical Oncology, Enam Medical College Hospital, Savar, Dhaka, Bangladesh

*Corresponding author: H. N. Ashikur Rahaman, Registrar, Dept. of Clinical Oncology, Enam Medical College \& Hospital, Savar, Dhaka, Bangladesh.

Received Date: April 26, 2021; Accepted Date: May 04, 2021; Published Date; May 07, 2021.

Citation: H. N. Ashikur Rahaman, (2021) Program Against Cancer in Samoa. J. Clinical Oncology Research and Reports. 2(2). Doi:10.31579/26934787/026

Copyright: @ 2021 H. N. Ashikur Rahaman. This is an open-access article distributed under the terms of the Creative Commons Attribution License, which permits unrestricted use, distribution, and reproduction in any medium provided the original author and source are credited.

\begin{abstract}
Introduction: Breast pain also known as mastalgia is the dull acne in the breast, cause is multifactorial. It can affect any age group. Breast cancer is the most common site-specific cancer in women and is the leading cause of death from cancer for women aged 20-59 years worldwide. In India, breast cancer has ranked number one cancer among females, with age adjusted incidence as high as 25.8 per 100,000 women and mortality 12.7 per 100,000 women.
\end{abstract}

Objective: To find out the Clinical and USG Findings of Patients Presented with Breast Pain.

Settings and Design: Prospective cross-sectional descriptive study.

Materials and Methods: Patients with complaints of breast pain in the age group 15 to 60 years with clinically no palpable mass attending to the Dept. of Clinical Oncology, Enam Medical College \& Hospital, Savar, Dhaka, Bangladesh between January 2020 to December 2020 were included in the study. Detailed history with particular reference to age, duration of symptoms, Size, menstruation, marital status, parity, lactation, Nipple discharge and tenderness are recorded. Pain intensity was evaluated as mild, moderate and severe. Ultrasound of the breast including the axilla was done for all cases and findings recorded to correlate with clinical features.

Results: Out of 90 patients studied, majority was in the age group (21-30) years, (43\%) followed by (31-40 years) (40\%) respectively. 57(63\%) were married and 33(43\%) were single. 21 patients had 1 child, 18 had 2 children with 6 of them having no children. Out of 90 patients only 3 attained menopause, rest of them have their monthly cycles. 51 patients had cyclical breast pain and 39 had noncyclical breast pain, 39 had pain on right breast, 36 on left side and bilateral in 15 patients. Pain was mild in 15 patients, moderate in 27 patients and severe in 6 patients. Various USG findings of the affected breast were normal study in 48 patients followed by duct ectasia and hetrogenous ectogenicity fibroadenosis, small cystic lesion and enlarged axillary lymph nodes etc.

Conclusion: The study results show that majority of patients with breast pain without clinically palpable lump had normal USG study. But it also detects other early changes in the breast tissue. It can be used as a baseline investigation for any breast pain without palpable lump.

Keywords: breast pain; breast cancer; palpable mass; usg findings; axillary lymph nodes

\section{Introduction}

Mastalgia is defined as pain, dull ache, discomfort or heaviness in the breast. It's commonly experienced by women, present up to $69 \%$ of women and can affect any age group. Etiology of breast pain is multifactorial. It may be due to normal cyclical changes in hormone level or due to certain diseases. ${ }^{1}$ So, it can be cyclical, non cyclical with peak incidence between (35-45) years. ${ }^{2}$ Cyclical hormonal changes are the most common cause of breast pain. Breast cancer is rarely cancer of breast pain according only $1.2-6.7 \% .^{3}$ Causes of mastalgia without clinical findings of Modularity or lump are still a challenge for diagnosis and management. Ultrasound of the breast is one of the most convenient, painless, and easily available and less costly investigation that can be done in women complaining of breast pain. ${ }^{4}$ Breast imaging provides reassurance to the women presenting with breast pain without lump according to Wayne state university study in $2008 .{ }^{3}$ The cross sectional study utility of breast imaging in mastalgia by nasreennath. et $\mathrm{al}^{4}$. In 2013 showed that Duct ectasia is a major factor in determining the severity of mastalgia with no significance between clinical and non clinical 
mastalgia. Hence breast imaging helps to identify the underlying pathology. 5

\section{Materials and Methods}

Patients with complaints of breast pain in the age group 15 to 60 years with clinically no palpable mass attending to the Dept. of Clinical Oncology, Enam Medical College \& Hospital, Savar, Dhaka, Bangladesh between January 2020 to December 2020 were included in the study. This was a prospective cross-sectional descriptive study. Detailed history with particular reference to age, duration of symptoms, Size, menstruation, marital status, parity, lactation, Nipple discharge and tenderness are recorded. Pain intensity was evaluated as mild, moderate and severe.
Clinical findings with reference to tenderness and quadrants involved are recorded. Then Ultrasound of the affected breast including the axilla was done in all the cases.

\section{Results}

Out of 90 patients studied, majority was in the age group (21-30) years, (43\%) followed by (31-40 years) (40\%) respectively. 57(63\%) were married and 33(43\%) were single. 21 patients had 1 child, 18 had 2 children with 6 of them having no children. Out of 90 patients only 3 attained menopause, rest of them have their monthly cycles as shown in the table below:

\begin{tabular}{|l|l|c|c|}
\hline S. No. & $\begin{array}{l}\text { Characteristics } \\
\text { (age in years) }\end{array}$ & Number & Percentage \\
\hline 1 & $15-20$ & 9 & $10 \%$ \\
\hline 2 & $21-30$ & 39 & $43 \%$ \\
\hline 3 & $31-40$ & 36 & $40 \%$ \\
\hline 4 & $41-60$ & 6 & $6.6 \%$ \\
\hline
\end{tabular}

Table 1: Demographic distribution of study patients.

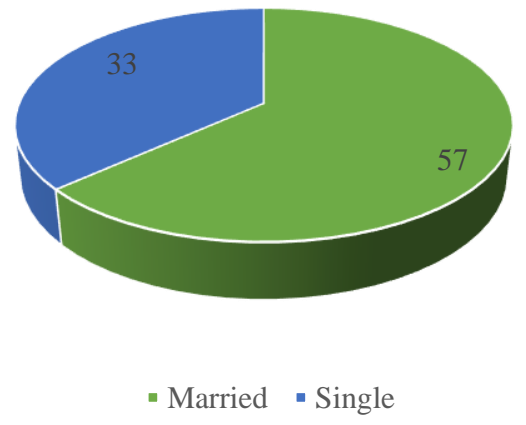

Table 2: Marrital status.

\begin{tabular}{|l|l|l|}
\hline S. No. & No. of Children & No. Of Patients \\
\hline & No Children & 6 \\
\hline & 1-Children & 21 \\
\hline & 2-Children & 18 \\
\hline & 3-Children & 9 \\
\hline & 4 And Above & 3 \\
\hline
\end{tabular}

Table 2: Children status of women.

In this study out of 90 patients, 51 (56) patients had cyclical breast pain and 39 (34) had non cyclical breast pain. The pain was on right side in 39 (34) patients, 36 (40) on the left and bilateral in 15 (16) patients. Majority of pain were in right lower outer quadrant (27) and left upper quadrants
(18). The intensity of the pain was mild in 57 (65), moderate in 27 (30), and severe in 6 (6), patients according to visual analog scoring (VAS) system.

\begin{tabular}{|l|l|l|l|}
\hline S. No. & Characteristics & Number & Percentage \\
\hline & Type of Pain & & \\
& Cyclical & 51 & 56 \\
& Noncyclical & 39 & 34 \\
\hline & Side affected & & \\
\hline
\end{tabular}




\begin{tabular}{|l|l|l|l|}
\hline & Right & 39 & 34 \\
& Left & 36 & 40 \\
& Bilateral & 15 & 16 \\
\hline & Severity of Pain & & \\
& Mild & 57 & 63 \\
& Moderate & 30 & 33 \\
& Severe & 3 & 3 \\
\hline
\end{tabular}

Table 3: Characteristics of breast pain in the study.

In the USG examination of the affected breast and axilla are found normal study in $48(53 \%)$ patients, duct ectasia in $12(13 \%)$, multiple small cystic lesions in $9(10 \%)$, fibroadenosis in $9(10 \%)$ patients. Heterogonous ectagenecity with probe tenderness in $4(4 \%)$, Hypoechoeic demarcated nodules $4(4 \%)$ and fibroadenosis in $3(3 \%)$ and enlarged axillary lymph node $1(1 \%)$ respectively as shown in the table below:

\begin{tabular}{|l|c|c|c|}
\hline S. No. & Findings & Numbers of Patients & Percentage \\
\hline 01 & Normal & 48 & 53 \\
\hline 02 & Duct Ectasia & 12 & 13 \\
\hline 03 & Multiple Small Cystic Lesions & 9 & 10 \\
\hline 04 & Fibroadenosis & 9 & 10 \\
\hline 05 & $\begin{array}{l}\text { Ectagenecity With Probe } \\
\text { Tenderness }\end{array}$ & 4 & 4 \\
\hline 06 & Hypoechoeicdemarcated Nodules & 3 & 4 \\
\hline 07 & Fibroadenosis & 1 & 3 \\
\hline 08 & Enlarged Axillary Lymph Node & 4 \\
\hline
\end{tabular}

Those patients with mass lesions were further subjected to FNAC but no malignancy was detected. FNAC of axillary lymph nodes showed non specific reactive Lymphadenitis.

Table 4: Ultra Sound findings of the affected breast.

\section{Discussion}

Risk increases by almost $3 \%$ for each year older at menopause thus women who have attained menopause at 55 years rather than 45 years, has approximately $30 \%$ higher risk. In this study, majority of the women reached menopause after the age of 45 years. Risk of developing breast cancer increased in both pre-and post-menopausal patients who had early onset of menarche and late menopause possibly due to the increase in the duration of hormonal exposure15. In our study more patients were postmenopausal 64\% (16 patients) than premenopausal 36\% (9 patients). Similar profile can be seen in Karlsso N YA et al series. ${ }^{6,7}$ In Sandhu DS et $\mathrm{al}^{8}$ study $44.27 \%$ of the patients were premenopausal and $55.76 \%$. Karlsson YA et al reported $41 \%$ premenopausal and 59\% postmenopausal. Compared to the west the percentage of premenopausal patients are less in this study. Early age at first full-term pregnancy is inversely related to breast cancer risk. ${ }^{9}$ This association perhaps reflects either a pregnancy induced maturation of mammary cells, and thus making them less susceptible to carcinogenic transformation or a long lasting hormonal change or both. ${ }^{10}$ In this study, it was found that the majority of the women were at an age younger than 30 during their first pregnancy. However, information regarding the age at last pregnancy was not clear. Late age at last full term pregnancy also has been found to be associated with a higher risk of breast cancer, but not in all studies. ${ }^{11} \mathrm{High}$ parity has generally been associated with low breast cancer risk in previous epidemiological studies. Nulliparity was associated with an overall increased risk of breast cancer. In our study it was found that many women presented with breast cancer despite of high parity. ${ }^{12}$

\section{Conclusion}

The study results show that majority of patients with breast pain without clinically palpable lump had normal USG study. But it also detects other early changes in the breast tissue. It can be used as a baseline investigation for any breast pain without palpable lump.

\section{References:}

1. Kumar HC, Khadri SI, Kemparaj T, et al.(2014) Benign breast diseases: our institutional experience. JEMDS; 3(62):1363713644.

2. Memon A, Parveen S, Sangrarasi AK, et al.(2007) Changing pattern of benign breast lumps inyoung females. World J Med Sci ; 2(1):21-24.

3. Morris KT, Pommier RF, Morris A, et al. (2001) 100 Usefulness of the triple test score for palpable breast masses. Arch Surg; 136(9):1-10013.

4. Johnsen C. (1975). Breast disease. A clinical study with special reference to diagnostic procedures. Acta Chir Scand Suppl; 454:1108.

5. Bassett LW, Ysrael M, Gold RH,et al. Usefulness of mammography and sonography in women less than 35 years of age. Radiology1991; 180(3):831-835.

6. Ertem G, Kocer A. (2009). Breast examination among nurses and midwives in Odemis health district in Turkey. Indian J Cancer; 46(3):208-213.

7. hekwaba FN. (1994). Benign breast disease in Nigerian women: a study of 657 patients. J R Coll Surg Edinb; 39(5):280-283. 
8. Greenberg R, Skornick Y, Kaplan O. (1998). Management of breast fibroadenomas. J Gen Intern Med; 13(9):640-645.

9. Nadia AG. (2012). Benign breast disorders-a histopathological studyin Tikrit city.Diyala J Med; 3(1):27-35.

10. Gupta A, Gupta AK, Goyal R, et al. (2015). A study of clinical profile of benign breast diseases presenting at a tertiary care centre in central India. Scholar J Appl Med Sci; 3(2C):695-700.

11. Chaudhary IA, Qureshi SK, Rasul S, et al. (2003). Pattern of benign breast diseases. J Surg Pak; 8:5-7.

12. Sharma A, Chanchlani R. (2015). A study of spectrum of benign breast disease in a tertiary care institute of central India. J Evi Based Med Healthcare; 2(5):551-555. 